\title{
PROTOTYPE ANALISA SISTEM INFORMASI PENILAIAN E-RAPORT MENGGUNAKAN SWOT
}

\author{
Deden Rustiana ${ }^{1}$ \\ Muhammad Faisal $^{2}$ \\ Lina Iamayanti ${ }^{3}$ \\ Dosen AMIK Raharja Informatika ${ }^{1}$, Dosen STMIK Raharja ${ }^{2}$, Mahasiswa STMIK Raharja ${ }^{3}$ \\ e-mail: deden.rustiana@ raharja.info ${ }^{1}$, m.faisal@ raharja.info $^{2}$, lina@ raharja.info $^{3}$
}

\begin{abstract}
ABSTRAKSI
Dahulu teknologi informasi belum banyak digunakan dan penggunanya pun masih belum banyak yang bisa mengoprasikan sistem komputer, namun semakin majunya negara ini, terutama di indonesia yang sudah mulai menerapkan teknologi yang canggih, terutama dalam sistem informasi, karena dalam suatu perusahaan dan intasi sekolah sangat diperlukan sistem teknologi ini untuk membantu serta memudahkan pekerjaan, dalam sistem ini juga berguna sebagai media penyimpanan yang besar dalam sebuah database sistem, untuk membangun sebuah sistem metodologi yang digunakan yaitu metode pengumpulan data, untuk menganalisis sistem menggunkan metode swot, dan bahasa pemograman unified modeling language (UML), untuk menggambarkan sistem kedalam diagram peneliti menggunakan metode use case diagram, activity diagram,sequence diagram,dan rancangan sistem menggunakan Prototype.
\end{abstract}

Kata Kunci: Analisa swot, Use case diagram, Uml, Rancangan prototype.

\begin{abstract}
Formerly information technology has not been widely used and users are still not many who can mengoprasikan computer system, but the more advanced this country, especially in Indonesia who have begun to implement sophisticated technology, especially in information systems, because in a company and intasi school is necessary system this technology is also useful as a large storage medium in a system database, to build a methodology system used is data collection methods, to analyze the system using swot method, and programming language unified modeling language (UML ), to describe the system into the diagram of the researcher using the use case diagram, activity diagram, sequence diagram, and system design using Prototype.
\end{abstract}

Keywords: Swot analysis, Use case diagram, Uml. Prototype design.

\section{PENDAHULUAN}

\section{A. Latar belakang}

Dalam dunia pendidikan merupakan tempat untuk meningkatkan kualitas manusia dan meningkatkan mutu pendidikan itu sendiri, namun didunia pendidikan memiliki kendala akan akses sistem untuk memperbaiki infrastruktur yang ada, meskipun di indonesia teknologi sudah mulai berkembang tetapi dampak negatif yang diberikan begitu banyak sehingga setiap sistem yang diterapkan harus tetap diawasi, agar berkurangnya dampak yang tidak diinginkan dalam penelitian ini akan dibuatkannya sebuah sistem informasi untuk pendidikan salah satunya adalah sistem penilaian siswa yang menggunakan komputer karena sampai saat ini masih banyak sekolah-sekolah yang menggunakan sistem manual, untuk mencetak laporan nilai siswa masih menggunakan buku raport.

Oleh karena itu, Kami memilih instansi sekolah pada SMP Nurul Hidayah untuk dijadikan objek penelitian. Dalam kasus ini ternyata sekolah belum memaksimalkan komputerisasi untuk pengolahan 
data terutama pada data nilai siswa. Sistem yang sedang berjalan memang sudah menggunakan eraport yang diberikan oleh pemerintah namun masih belum di implementasikan untuk keseluruh siswa dan masih menggunakan buku raport, sehingga siswa harus datang kesekolah bersama walinya untuk mengambil raport, sehingga membutukan waktu dan tenaga.

Pada sistem pengolahan data nilai yang akan dibangun nantinya akan dijadikan website namun dalam hak aksesnya saja yang akan berbeda. Sistem ini hanya bisa dipakai oleh siswa, wali murid, wali kelas, guru mata pelajaran, admin, dan kepala sekolah hanya saja untuk siswa dan wali murid hanya bisa melihat sistem tersebut. Untuk wali kelas hak akses yang diberikan yaitu untuk memberi nilai prestasi dan catatan untuk siswanya. Untuk hak akses guru mata pelajaran hanya bisa menginput nilai siswa, untuk hak akses admin bisa mengoprasikan seluruh sistem tersebut, dan untuk kepala sekolah hanya bisa menerima laporan untuk mengetahui nilai-nilai siswa yang berkembang dan yang tidak.

\section{B. Tujuan penelitian}

Tujuan penelitian ini didasarkan pada permasalahn yang ada di instansi tersebut antara lain:

1. Bagaimana menerapkan sistem yang terkomputerisasi pada raport siswa

2. Mempercepat penilaian raport

3. Untuk memudahkan siswa melihat hasil nilai

\section{C. literatur review}

1. Penelitian yang telah dilakukan oleh nataniel dengen dan dyna marisa Kh [2009] judul "SISTEM INFORMASI AKADEMIK BERBASIS WEB SMP NEGRI 4 SAMARINDA". Dari hasil penelitian, perancangan dan implementasi Sistem informasi akademik berbasis web dibuat bersifat intern, artinya pengguna program ini hanya kalangan tertentu yang memiliki hak akses terhadap sistem ini yaitu siswa, pengajar dan administrator. Sistem informasi akademik berbasis web ini dirancang sebagai solusi bagi pihak SMP Negeri 4 Samarinda untuk mengelola bagian akademik dalam penyajian laporan nilai serta keaktifan siswa secara cepat dan tepat dibandingkan secara manual sehingga kinerja dalam mencapai pekerjaan dapat diwujudkan secara lebih maksimal.

2. Penelitian yang telah dilakukan oleh tanti kristanti dan niluh gede redita [2012] judul "SISTEM INFORMASI NILAI SMPN 14 BANDUNG". Kesimpulan yang didapat dari pembangunan Sistem Informasi Nilai SMPN 14 Bandung adalah sebagai Sistem Informasi Nilai SMPN 14 Bandung dibuat berbasiskan website., dapat menampilkan hasil belajar siswa secara online. Dan Melalui Sistem Informasi ini Siswa dapat mendownload materi pelajaran dan melatih kemampuan dengan memanfaatkan fasilitas latihan soal.

3. Penelitian yang dilakukan oleh susy kusuma wardani, [2013] judul "SISTEM INFORMASI PENGOLAHAN DATA NILAI SISWA BERBASIS WEB PADA SEKOLAH MENENGAH KEJURUAN (SMK) PGRI 1 PACITAN". Dari penelitian yang penulis lakukan dapat dilihat bahwa pengolahan data nilai untuk menghasilkan Pacitan apabila dengan menggunakan sistem konvensional atau sistem yang lama tidak efektif dan efisien. Karena disebabkan masih adanya perbedaan informasi yang dibutuhkan oleh pihak SMK PGRI dalam penulisan nilai atau kesalahan dan juga keterlambatan, Sedangkan penggunaan sistem yang baru dengan berbasis komputer khususnya dengan software aplikasi yang telah penulis buat dapat menghasilkan informasi yang berkualitas dan dapat membantu dalam proses pengambilan keputusan. Karena sistem ini terkomputerisasi mempunyai banyak keuntungan terutama dalam hal pengolahan data.

4. Penelitian yang dillakukan oleh bimo seto prakoso, dan meliana christianti [2008] yang berjudul "ANALISIS DAN PERANCANGAN SISTEM INFORMASI AKADEMIK DENGAN STUDI KASUS PADA SEKOLAH MENENGAH ATAS TERPADU (SMAT) KRIDA NUSANTARA". Aplikasi Sistem Informasi Akademik SMAT Krida Nusantara ini memiliki kemampuan yaitu Menyimpan data nilai siswa. Menyimpan data pelajaran, kompetensi dasar dan indikator. Memberikan informasi kepada orang tua siswa melalui fasilitas Berita. Memberikan wadah untuk berinteraksi dua arah melalui fasilitas Forum. Menyimpan data siswa. Dan Menghitung nilai ratarata nilai per kelas maupun per siswa.

5. Penelitian yang dilakukan ita purnama, dan erik hadi saputra yang berjudul "SISTEM INFORMASI RAPORT BERBASIS WEB DI SMP N 4 TEMANGGUNG". Masalah yang saat ini terjadi dapat diatasi dengan menggunakan website yang telah dibangun oleh penulis. Dan Testing 
yang digunakan terhadap sistem baru ini dilakukan saat pembuatan program, sebelum penerapan sistem. Uji cobanya dilakukan dengan metode white-box dan metode black-box. Dengan sistem baru ini dapat meminimalisir terjadinya pemborosan biaya serta keamanan data akan lebih terjaga.

\section{METODE PENELITIAN}

\section{A. Metode Analisa sistem}

\section{Analisa SWOT}

Untuk menemukan masalah - masalah yang akan ditemui maka diadakan analisis terhadap sistem yang sedang berjalan untuk menemukan faktor - faktor yang berpengaruh terhadap kelemahan dan kekuatan sistem sehingga sistem baru dapat mengatasi kelemahan tersebut. Faktor - faktor yang terdapat pada analisis SWOT dapat berupa Kekuatan (Strenghts), Kelemahan (Weaknesses) ,Kesempatan (Opportunity) dan Ancaman (Threat). (Nisak, Zuhrotun. 2013.)

Tabel 1. Analisa SWOT

\begin{tabular}{|l|l|}
\hline FAKTOR INTERNAL \\
\hline Kekuatan $(S)$ & Membutuhkan biaya yang sedikit \\
\hline Kelemahan $(W)$ & $\begin{array}{l}\text { Pengumpulan nilai siswa kurang cepat } \\
\text { Data nilai siswa bisa saja di ubah oleh pihak lain } \\
\text { Data nilai siswa kurang terkoordinasi dengan baik }\end{array}$ \\
\hline \multicolumn{2}{|c|}{ FAKTOR EKSTERNAL } \\
\hline Kesempatan $(O)$ & $\begin{array}{l}\text { Dibutuhkannya suatu sistem yang mengontrol dan } \\
\text { menangani data nilai yang efisien dan realtime } \\
\text { Pemberkasan nilai siswa yang lebih mudah dan } \\
\text { efisien } \\
\text { Belum banyak sekolah yang menggunakan sistem ini }\end{array}$ \\
\hline Ancaman $(T)$ & $\begin{array}{l}\text { Perkembangan sistem informasi yang semakin cepat } \\
\text { dan canggih }\end{array}$ \\
\hline
\end{tabular}

\section{B. Perangkat lunak untuk Pengembangan Sistem}

Untuk mengimplementasikan sistem penilaian rapor ini, diperlukan beberapa perangkat untuk membangun sistem tersebut diantaranya :

1. PHP

Menurut betha sidik (2014) PHP merupakan secara umun dikenal sebagai bahasa pemograman scrip-script yang membuat dokumen html yang dieksekusi diserver web, dokumen yang dihasilkan dari suatu editor teks atau editor html dikenal juga sebagai bahasa pemograman server side. Dengan menggunakan php maka main tenance suatu situs web menjadi lebih mudah, proses update data dapat dilakukan dengan menggunakan aplikasi yang dibuat dengan menggunakan php.

2. MySQL

Menurut (Firdaus 2007). MySQL merupakan sebuah tempat database yang menghubungkan script PHP dengan menggunakan perintah query dan escape character yang sama dengan PHP. MySQL mempunyai tampilan client yang mempermudah user dalam mengakses database dengan kata sandi untuk mengijinkan proses yang akan dilakukan. Kelebihan dari MySQL dapat melakukan transaksi dengan mudah dan efisien serta mampu menangani jutaan user dalam waktu yang bersamaan .

3. Unified Modeling Language (UML)

Menurut Prabowo (2011:6), Unifield Modeling Language (UML) adalah sebuah alat komunikasi bahasa yang berdasarkan diagram, deskripsi atau gambar untuk menvisualisasikan, menspesifikasi, membangun dan mendokumentasi dari sebuah sistem pengembang perangkat linak berbasis orientasi objek yang standart tujuan dari penciptaan UML adalah untuk menyediakan kosakata umum berbasis objek dan diagram teknik yang 
cukup efektif untuk memodelkan setiap proyek pengembangan sistem mulai tahap analisis sampai tahap desain dan implementasi (dennis dkk, 2012:513), semua dibuat dengan kebutuhan, diagram yang sering digunakan adalah diagram use case, diagram aktivitas, diagram sequence, diagram class.

a) Use Case Yang Diusulkan

Use Case Diagram menggambarkan fungsional yang diharapkan dari sebuah sistem yang nantinya akan dibangun. Berikut penjelasan use case diagram pada gambar dibawah ini

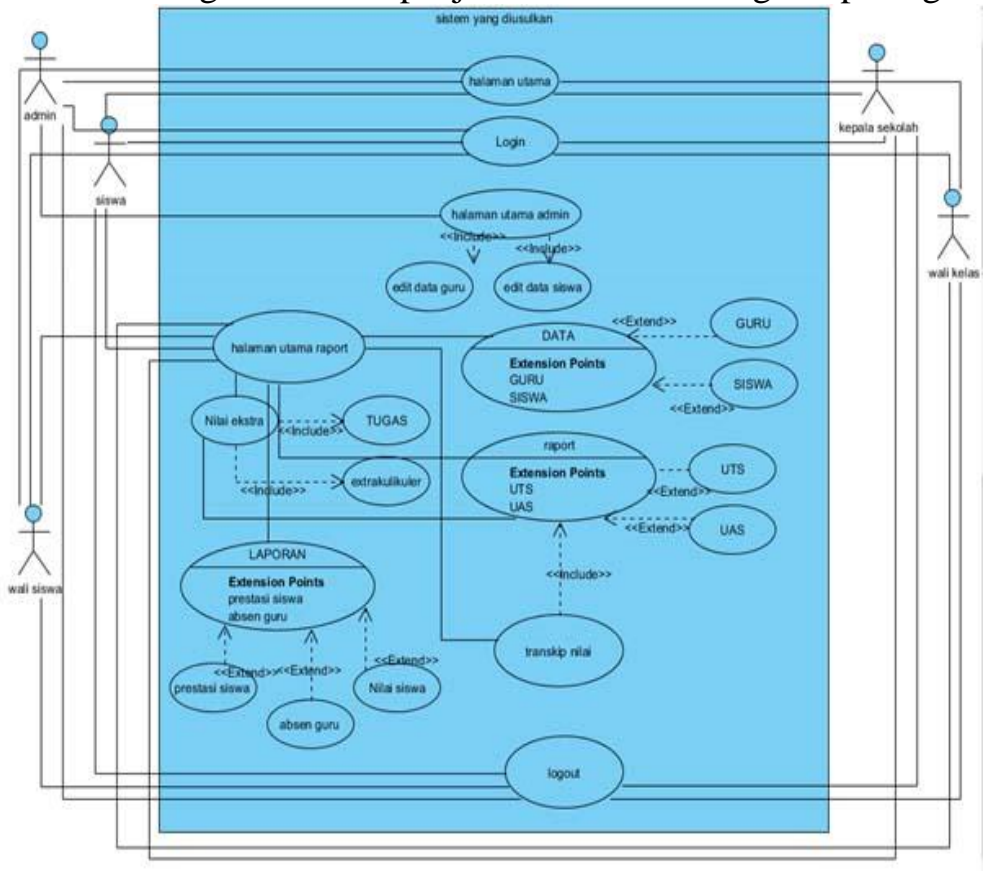

Gambar 1. Usecase Yang Diusulkan

Berdasarkan pada gambar usecase diatas terdiri dari :

1. Satu sistem yang mencakup kegiatan penilaian raport siswa

2. Terdiri dari 5 aktor yang melakukan kegiatan didalam sistem yaitu wali kelas, siswa,wali siswa, dan admin.

3. Terdapat lima use case yang dapat dilakukan aktor tersebur yaitu halaman awal,menu login, halaman untuk admin, tampilan raport dan logout.

4. Terdapat include, yaitu ; edit data guru, edit data siswa, nilai ekstra, nilai tugas, nilai ekstrakulikuler, nilai uts, nilai uas, dan transkip nilai.

b) Activity Diagram

Activity diagram yang menggambarkan alur aktifitas dalam sebuah sistem yang sedang dirancang, untuk mengetahui aktifitas semua aktor yang berbeda-beda sesuai alur masing-masing, decision yang mungkin terjadi dan bagaimana mereka berakhir. Berikut penjelasan activity diagram pada gambar dibawah ini. 

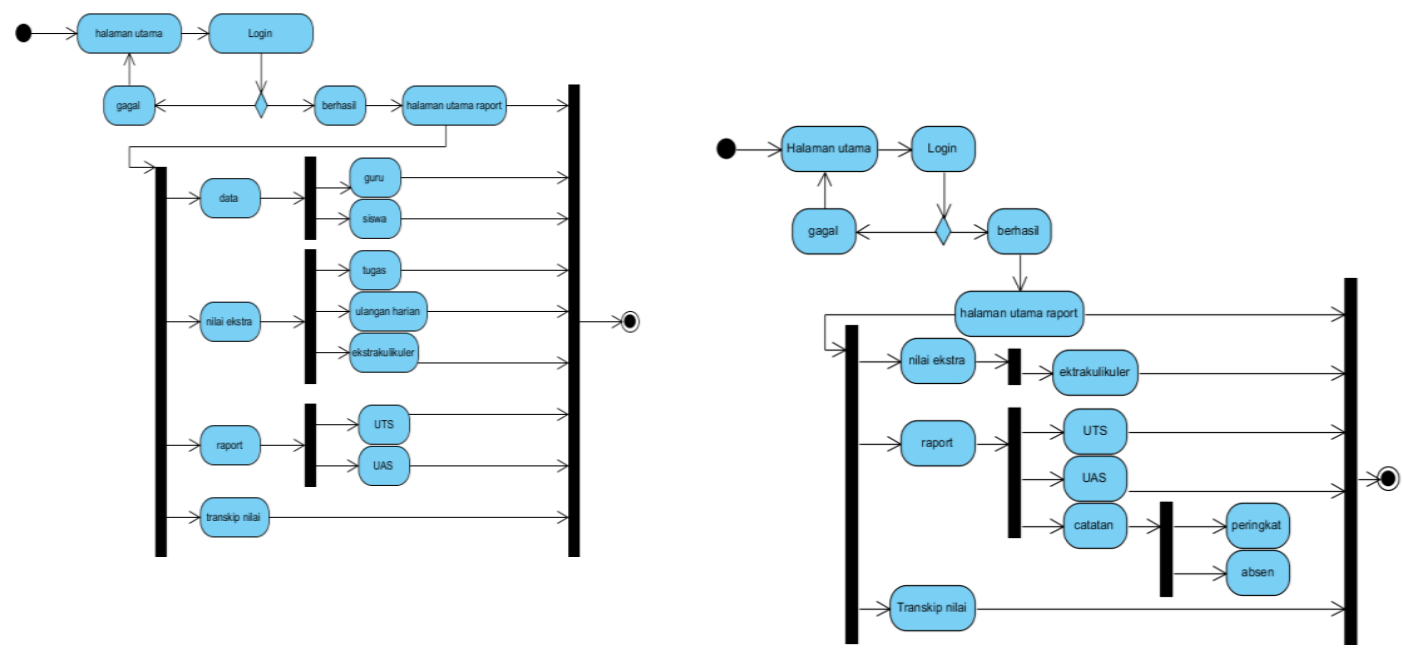

Gambar 2. Activity Diagram Usulan Pada Sistem Siswa

Gambar 3. Activity Diagram Usulan Pada Sistem Wali Kelas
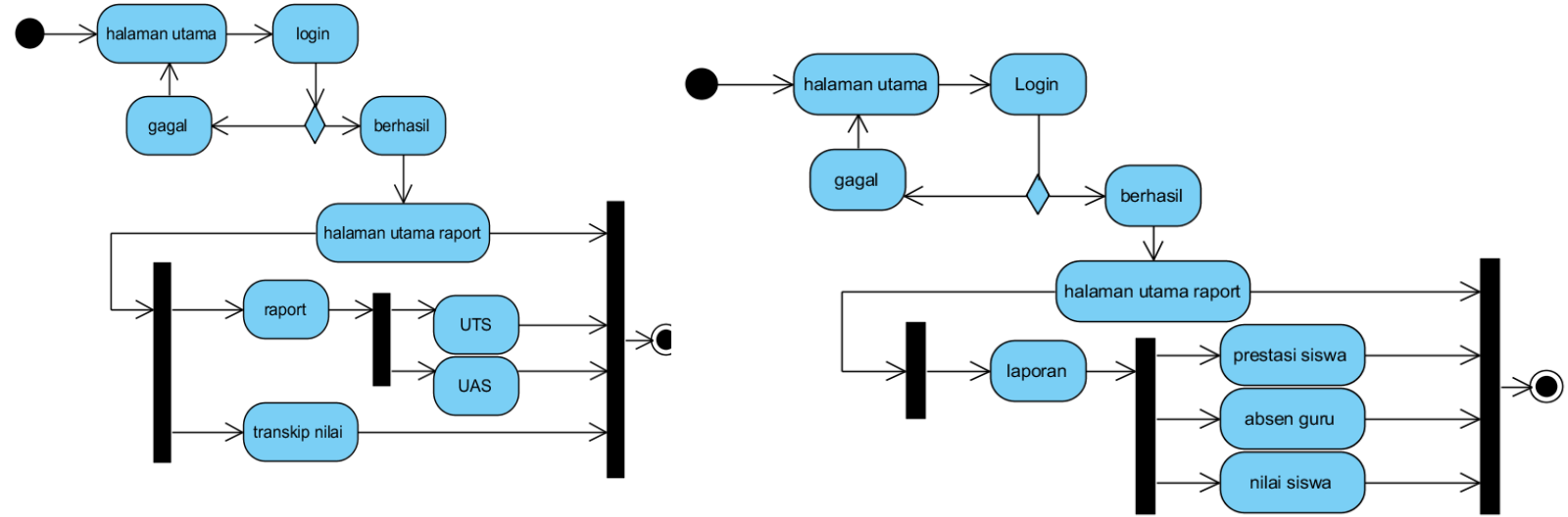

Gambar 4. Activity Diagram

Gambar 5. Activity

Usulan Pada Sistem Wali siswa

Diagram Usulan Pada Sistem Kepsek

\section{HASIL PENELITIAN DAN PEMBAHASAN}

Kebutuhan sistem informasi yang akan diterapkan pada instansi sekolah yang difokuskan kepada nilai siswa akan digunakan sebagai media sarana informasi , untuk mengetahui siswa disekolah akan hasil laporan nilai mereka yang dapat diakses secara online dalam sebuah website jadi tidak memakan waktu untuk datang kesekolah karna semua laporanya sudah tertera didalam database sekolah dan bisa diakses dimana saja dan kapan saja, dibangunnya sistem penilaian raport berbasis web ini untuk membantu pihak sekolah dalam penyampaian informasi kepada siswanya, agar kinerja suatu pekerjaan dapat diwujudkan lebih. 


\section{a. Struktur Menu Sistem}

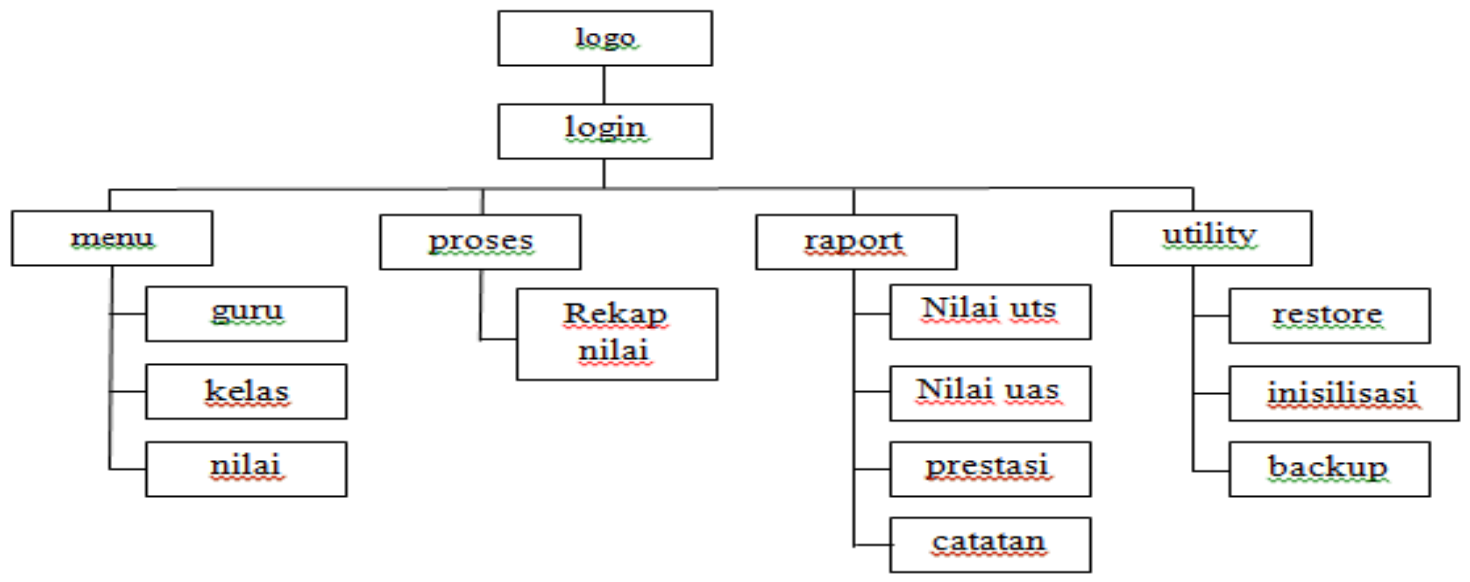

Gambar 6. Struktur menu sistem

B. Rancangan Sistem Menggunakan Prototype

\section{Rancangan halaman utama}

Halaman ini berisi slide foto - foto sarana dan prasarana SMP Nurul hidayah dan mengenai hal-hal yang bersangkutan disekolah. seperti pada gambar berikut ini:

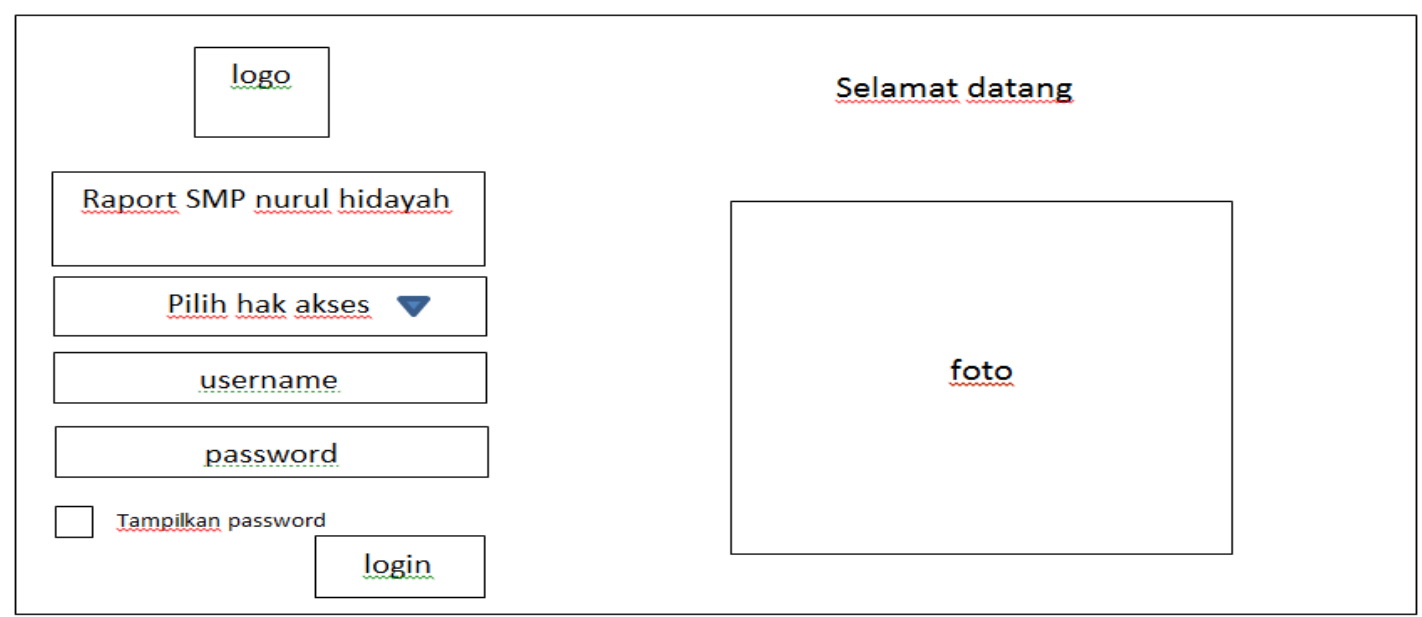

Gambar 7. Rancangan tampilan halaman utama

2. Tampilan menu siswa ketika berhasil login.

Halaman ini berisi biodata, dengan tertera photo siswa, seperti pada gambar berikut ini:

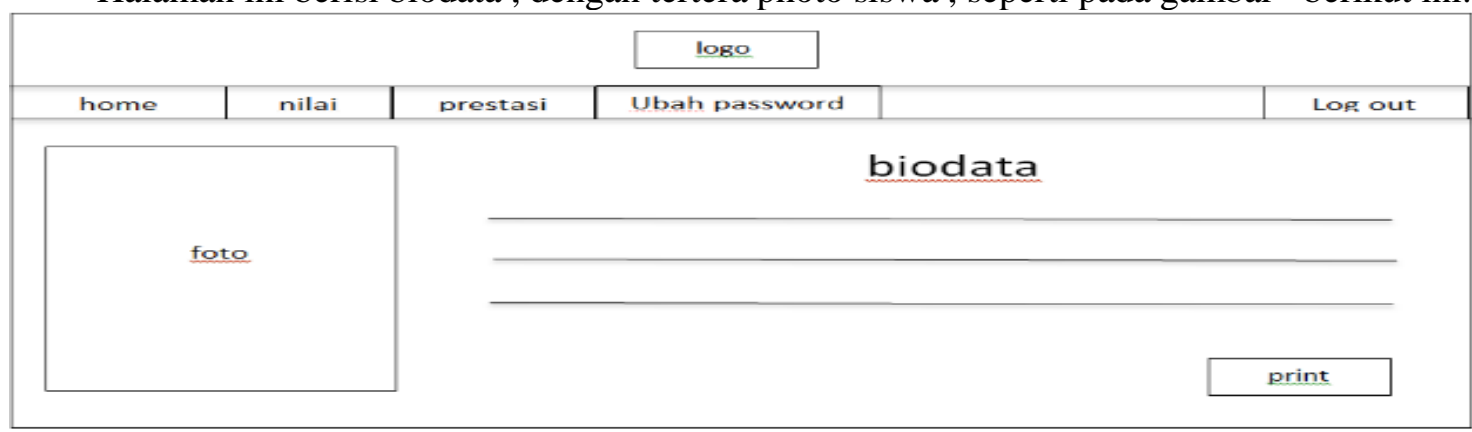

Gambar 8. rancangan halaman menu siswa berhasil login 
3. Tampilan menu untuk nilai

Halaman ini berisi nilai UTS, UAS dan nilai tugas seperti pada gambar berikut ini:

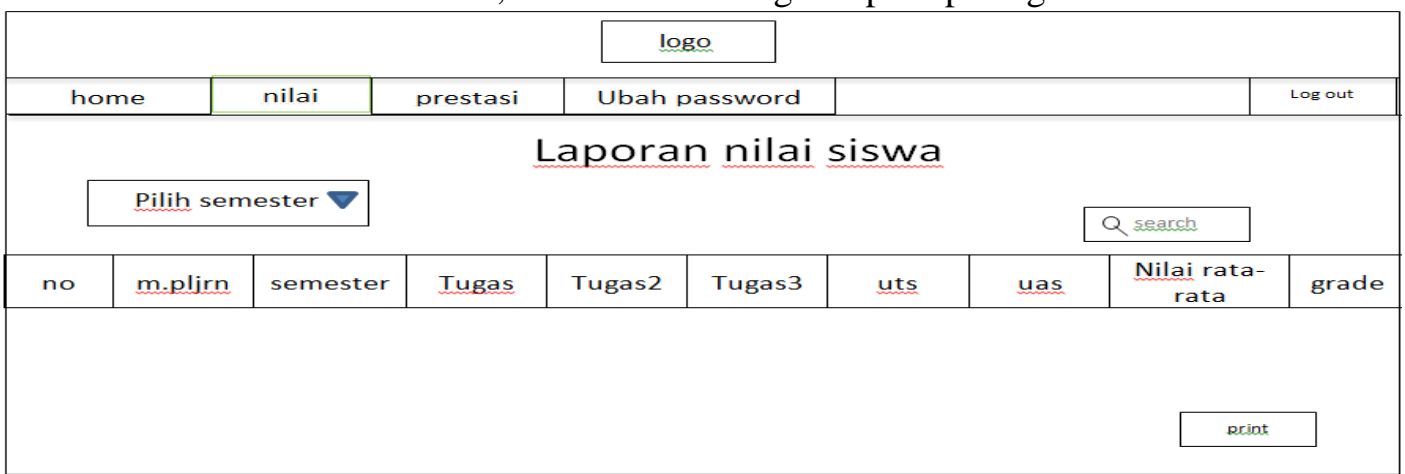

Gambar 9. Rancangan Tampilan Menu Untuk Nilai

\section{Tampilan menu untuk guru}

Halaman ini berisi profil guru, dan memasukan nilai atau mengedit nilai tugas, tugas 1, tugas 2, tugas 3, UTS , dan nilai UAS untuk siswa, seperti pada gambar berikut ini:

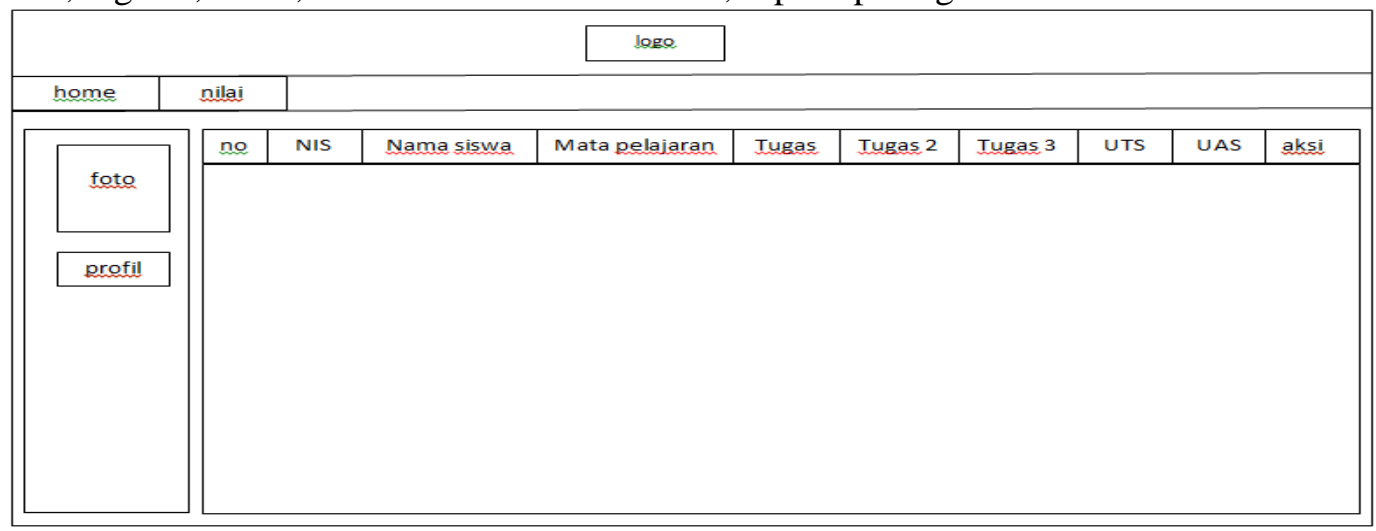

Gambar 10. Rancangan tampilan untuk menu guru

\section{Tampilan menu admin}

Halaman ini berisi pengolahan dari semua database yang terkait, menu ini terdapat jumlah siswa akademik, dan jumlah guru. Seperti pada gambar berikut:

\begin{tabular}{|c|c|c|c|c|}
\hline & & logo & & \\
\hline Home & Guru & Siswa & Akademik & Cetak \\
\hline Foto & $\begin{array}{l}\text { Jumlah siswa } \\
\text { keseluruhan }\end{array}$ & & Jumlah guru & \\
\hline Hak Akses & $\begin{array}{c}\text { Jumlah kelas } \\
\text { siswa }\end{array}$ & & $\begin{array}{c}\text { Jumlah mata } \\
\text { pelajaran }\end{array}$ & \\
\hline
\end{tabular}

Gambar 11. Rancangan tampilan untuk menu admin 


\section{Tampilan menu raport}

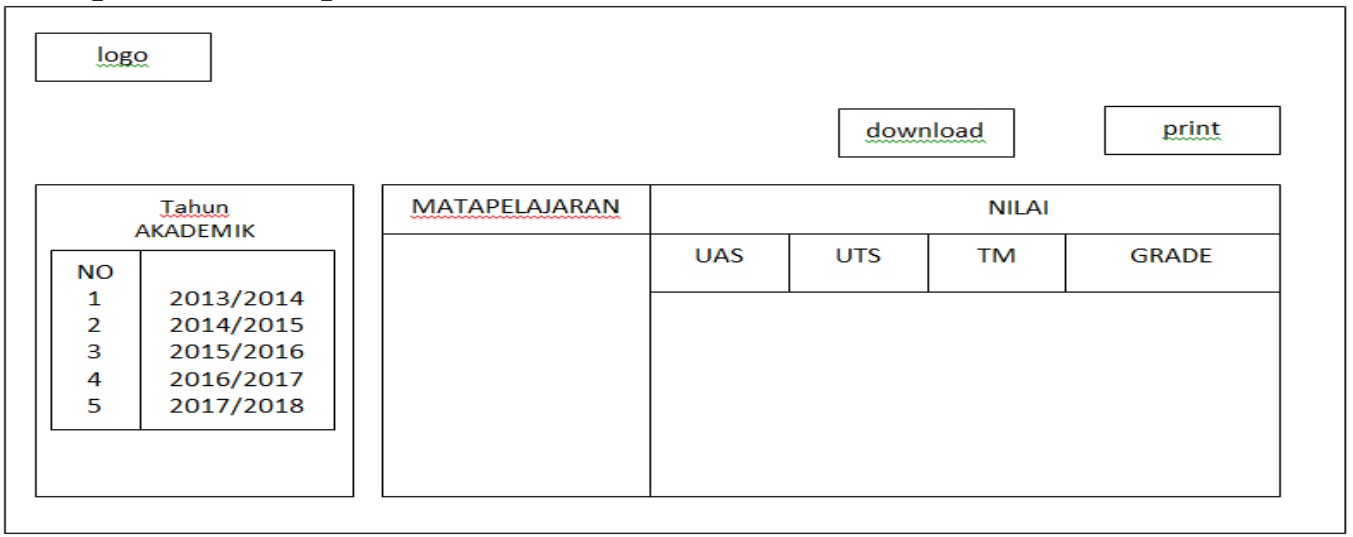

Gambar 12. Rancangan tampilan raport

\section{ANALISA MASALAH}

Agar memudahkan penelitian dalam pembahasan, maka perlu adanya pembatasan masalah yaitu:

1. Bagaimana mengimplementasi sistem penilaian ini dengan merancang sebuah website?

2. Bagaimana mengatasi permasalahan dalam mengolah nilai siswa yang sedang berjalan saat ini?

3. Sulitnya penyampaian dalam sistem informasi nilai uts, uas dan tugas mandiri.

\section{AlTERNATIF PEMECAHAN MASALAH}

1. Membangun aplikasi dan penjualan yang mudah dioprasikan, cepat, dan akurat.

2. Membangun aplikasi yang bersifat umum dan dapat dilihat oleh siswa.

3. Aplikasi dibuat menggunakan database sehingga dapat diupdate jika ada perubahan, serta aman dalam penyimpanan data.

\section{KESIMPULAN}

Dari pengamatan yang telah peneliti lakukan maka ada beberapa kesimpulan yang diambil untuk merumuskan masalah berikut ini:

1. Sistem penilaian raport yang berjalan saat ini belum sepenuhnya terkomputerisasi. Cara kerjanya adalah menerima berkas penilaian siswa dari setiap guru mata pelajaran setelah itu dicatat dalam buku kumpulan nilai dan menyalinnya kembali dalam satu buku yang disebut dengan raport. Setelah penyalinan tersebut raport disimpan dan dibagikan kepada setiap wali murid pada waktu penyerahan raport berlangsung. Dalam jangka waktu yang ditentukan oleh pihak sekolah, siswa diminta untuk mengembalikan raport tersebut kepada guru wali setiap kelas.

2. Kendala dalam penilaian raport yang berjalan saat ini pun adalah setiap siswa masing - masing mempunyai nilai yang berbeda - beda, sehingga membutuhkan waktu yang sangat lama dalam pengerjaannya.

3. Dalam menganalisa sistem yang sedang berjalan peneliti menggunakan beberapa metodelogi yaitu metode pengumpulan data, metode analisa swot, metode analisis data dan metode prototype.

\section{SARAN}

Dalam penerapan sistem yang berjalan peneliti ingin menyampaikan saran - saran agar sistem bisa berjalan dengan baik, diantaranya:

1. Untuk mengoptimalkan pekerjaan, alangkah baiknya sistem penilaian raport yang dilakukan secara manual diperbaharui dengan menerapkan sistem yang terkomputerisasi.

2. Dengan sistem yang terkomputerisasi dalam proses pengolahan data bisa lebih cepat dan data yang dihasilkan akan lebih akurat. 
3. Peneliti mengusulkan untuk dibuatnya sistem berbasis website agar sistem dapat diakses dimana saja.

\section{UCAPAN TERIMAKASIH}

Puji syukur penulis ucapkan kehadirat Allah SWT yang sudah menganugerahkan rahmatnya karena dengan itu, peneliti sanggup mengerjakan karya ilmiah ini, terimaksih juga terhadap pihak-pihak yang bersangkutan tanpa adanya mereka mungkin penulisan ini tidak akan terselesaikan.

\section{DAFTAR PUSTAKA}

[1] Nisak, Zuhrotun. 2013. Analisis SWOT Untuk Menentukan Strategi Kompetitif. Jurnal EKBIS, Universitas Islam Lamongan, No.2, Vol. 9, :2.

[2] Widodo, Prabowo. P,Dkk. 2011 "Pemodelan Sistem Berorientasi Obyek Dengan UML" Graha Ilmu : Yogyakarta.

[3] Arief M Rudianto. 2011. Pemrograman Web Dinamis menggunakan PHP dan MySQL. C.V ANDI OFFSET. Yogyakarta.

[4] Firdaus 2007, 7 Jam Belajar Interaktif PHP dan MySQL dengan Dreamwaver: , Maxikom, Jakarta.

[5] Pressman, Roger S. 2012. "Rekayasa Perangkat Lunak". Yogyakarta.

[6] Hendri. 2007, analysis and design system with unified modeling language ( UML ). Tangerang, STMIK raharja

[7] Dengen, Nataniel., Marisa Kh, Dyna, 2009. Jurnal: Sistem Informasi Akademik Berbasis Web SMP Negeri 4 Samarinda. Samarinda: Universitas Mulawarman. Jurnal informatika mulawarman, Vol 4, No 2, juli 2009.

http://ejournals.unmul.ac.id/index.php/JIM/article/view/38/pdf

[8] Wardani, Susy. 2013 "sistem informasi pengolahan data nilai siswa berbasis web pada sekolah menengah kejuruan (smk) pgri 1 pacitan" Jurnal IJNS, Vol 1, No 1, http://majour.maranatha.edu/index.php/jurnal-sistem-informasi/article/view/pp.\%2085-94

[9] Prakoso, seto bimo. Chistianti, meliana. "Analisis dan Perancangan Sistem Informasi Akademik dengan Studi Kasus pada Sekolah Menengah Atas Terpadu (SMAT) Krida Nusantara” jurnal sistem informasi, no 1, vol 3, maret 2008 , 75-90. http://jutisi.maranatha.edu/index.php/jusi/article/view/233

[10] Sari, purnama ita, saputra, hadi erik. "SISTEM INFORMASI RAPORT BERBASIS WEB DI SMP N 4 TEMANGGUNG” jurnal ilmiah DASI, Vol 15, No 02 juni 2014: 24-28. https://ojs.amikom.ac.id/index.php/dasi/article/view/190

[11] Kristani, tanti . redita A.K, gede niluh. "Sistem Informasi Nilai SMPN 14 Bandung", Universitas Kristen Maranatha, jurnal sistem informasi, vol 7, no 1, maret 2012: 85-94. http://majour.maranatha.edu/index.php/jurnal-sistem-informasi/article/view/pp.\%2085-94 